\title{
Rotational Acetabular Osteotomy for Pre- and Early Osteoarthritis Secondary to Dysplasia Provides Durable Results at 20 Years
}

\author{
Yuji Yasunaga MD, Mitsuo Ochi MD, Takuma Yamasaki MD, \\ Takeshi Shoji MD, Sotaro Izumi MD
}

Published online: 27 April 2016

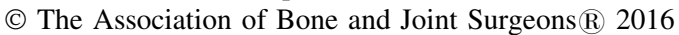

\begin{abstract}
Background Hip dysplasia is a common cause of secondary osteoarthritis (OA). Periacetabular osteotomy or rotational acetabular osteotomy has been used as jointpreserving procedures. However, only a few reports of long-term results with these operations have been reported. Questions/purposes (1) Would satisfactory clinical and radiographic outcomes be maintained at a mean duration of 20 years after rotational acetabular osteotomy for pre- and early-stage OA; and (2) could we identify risk factors for radiographic progression of $\mathrm{OA}$ ?
\end{abstract}

Each author certifies that he has no commercial associations (eg, consultancies, stock ownerships, equity interest, patient/licensing arrangements, etc) that might pose a conflict of interest in connection with the submitted article.

All ICMJE Conflict of Interest Forms for authors and Clinical Orthopaedics and Related Research ${ }^{\circledR}$ editors and board members are on file with the publication and can be viewed on request.

Clinical Orthopaedics and Related Research ${ }^{\circledR}$ neither advocates nor endorses the use of any treatment, drug, or device. Readers are encouraged to always seek additional information, including FDAapproval status, of any drug or device prior to clinical use. Each author certifies that his institution approved for the human protocol for this investigation and that all investigations were conducted in conformity with ethical principles of research. This work was performed at Hiroshima Prefectural Rehabilitation Center, Higashi-Hiroshima, Japan, and Hiroshima University Hospital, Hiroshima, Japan.

Y. Yasunaga $(\square)$

Department of Orthopaedic Surgery, Hiroshima Prefectural Rehabilitation Center, Taguchi 295-3, Saijo, Higashi-Hiroshima 739-0036, Japan

e-mail: yasuyuji@hiroshima-wsc.jp

M. Ochi, T. Yamasaki, T. Shoji, S. Izumi

Department of Orthopaedic Surgery, Hiroshima University, Hiroshima, Japan
Methods Between 1987 and 2001, we treated 159 patients (173 hips) with rotational acetabular osteotomies for the diagnosis of pre-OA or early-stage OA according to the technique of Ninomiya and Tagawa. During that period, our general indications for this approach were age younger than 60 years, center-edge angle less than $20^{\circ}$, and improved femoral head coverage and joint congruency on preoperative AP plain radiographs of the hip in abduction; we did not use this approach when joint congruency was not improved or no widening of the joint space was noted on preoperative AP plain radiographs of the hip in abduction. Of those patients, 21 patients with pre-OA (followup rate: $84 \%$ [27 hips]) and 110 patients in the early-stage group (followup rate: 82\% [118 hips]) were available at a minimum of 15 years for a total patient group of 131 (followup rate: $82 \%$ [145 hips]). The mean age at the time of surgery was 22 years in the pre-OA group and 38 years in the early-stage group. The mean followup was 21 years in the pre-OA group and 20 years in the earlystage group. Clinical evaluation was performed with the Merle d'Aubigne and Postel rating scale, and radiographic analyses included measurements of the center-edge angle, acetabular roof angle, and head lateralization index on preoperative and postoperative AP radiographs of the pelvis. Postoperative joint congruency was also evaluated. The cumulative probabilities of radiographic signs of OA progression were estimated with use of the Kaplan-Meier product-limited method and parametric survivorship analysis using the Cox proportional-hazards model was used to determine risk factors for radiographic OA progression. Results The mean clinical score improved very slightly, from 15 (SD, 0.8$)$ to 18 (SD, 1.1) (95\% confidence interval $[\mathrm{CI}],-2.9$ to $-2.0 ; \mathrm{p}<0.001)$ in the pre-OA group and from $15(\mathrm{SD}, 1.0)$ to $16(\mathrm{SD}, 2.1)(95 \% \mathrm{CI},-2.0$ to -1.2 ; $\mathrm{p}<0.001)$ in the early-stage group at followup. Fourteen 
patients (15 hips) including one pre-OA patient (one hip) and 13 early-stage patients (14 hips) experienced worsening of their Merle d'Aubigne and Postel score, from a mean of 15 (SD, 0.9) to 12 (SD, 1.6) (95\% CI, 1.8-3.3; p < 0.001). Eight patients (nine hips) with early-stage OA preoperatively underwent total hip arthroplasty at a mean duration after rotational acetabular osteotomy of 20 (SD, 2.5) years. Radiographic indices were improved after surgery in both groups. Radiographic progression of OA occurred in 24 patients (25 hips). Kaplan-Meier survivorship analysis, with radiographic signs of progression of OA as the endpoint, predicted survival of $96 \%$ (95\% CI, 89\%$100 \%$ ) at 10 years and 20 years in the pre-OA group. For the early-stage group, we found survivorship of $89 \%(95 \%$ CI, 83\%-95\%) at 10 years and $78 \%(95 \%$ CI, 69\%-87\%) at 20 years. We identified two factors associated with poor outcome: fair (rather than excellent and good) postoperative joint congruency (hazard ratio, 12.1; 95\% CI, 3.8-39; $\mathrm{p}$ $<0.001)$ and age older than 46 years at the time of surgery (hazard ratio, 4.6; 95\% CI, 1.9-11; $\mathrm{p}<0.01$ ).

Conclusions Rotational acetabular osteotomy is an effective surgical procedure for symptomatic dysplastic hips in pre- and early-stage OA, and it prevented radiographic OA progression and maintained hip function at a mean 20 years after surgery.

Level of Evidence Level IV, therapeutic study.

\section{Introduction}

Hip dysplasia is the most common cause of secondary osteoarthritis (OA) [1, 8, 10, 17, 18]. Four radiographic criteria are typically cited: acetabular angle, acetabular roof, acetabular depth, and center-edge angle. Although THA represents the treatment of choice for many patients, the option of a joint-preserving procedure is attractive. To prevent the early onset of secondary OA, a number of surgical procedures have been proposed [6, 7, 20, 21]. These procedures reorient the acetabulum to reduce superolateral acetabular inclination, improve femoral head coverage, translate the joint center medially, and normalize loading of the anterolateral acetabular rim [14, 20]. Typically, these procedures are performed before the onset of clinically evident severe disease.

However, the optimal procedure for treating hip dysplasia in the patient with pre-OA or early OA has not been elucidated [4, 25]. In 1987, we began performing the rotational acetabular osteotomy described by Ninomiya and Tagawa [20]. In this procedure, the entire acetabulum is osteotomized with only the joint capsule serving as an attachment. The acetabular fragment is then shifted anterolaterally, medially, and downward. Although the indications for rotational acetabular osteotomy are similar to those of the Bernese periacetabular osteotomy, including pain greater than 6 months, adequate ROM, radiographic evidence of residual hip dysplasia, and closure of triradiate cartilage, there are little long-term data published on the rotational acetabular osteotomy [9, 12, 19, 22].

We therefore asked the following: (1) Would satisfactory clinical and radiographic outcomes be maintained at long term? (2) Could we identify risk factors for radiographic progression of OA?

\section{Patients and Methods}

The study did not receive institutional review board approval because our institution does not require such approval for retrospective studies.

Between 1987 and 2001, we treated 159 patients (173 hips) with rotational acetabular osteotomies for the diagnosis of pre- or early-stage OA as a result of developmental hip dysplasia according to the technique of Ninomiya and Tagawa [20]. During that period, our general indications for this procedure were age younger than 60 years, centeredge angle less than $20^{\circ}$, and improved femoral head coverage and joint congruency on preoperative AP plain radiographs of the hip in abduction. We did not use this procedure when joint congruency was not improved or no widening of the joint space (the joint congruency; poor) on preoperative AP plain radiographs of the hip in abduction (Fig. 1) [24].

According to the criteria of the Japanese Orthopaedic Association (JOA), the preoperative radiographic OA stage was pre-OA in 25 patients (31 hips) and early-stage in 134 patients (142 hips). Of those patients, 21 patients with preOA (followup rate: 84\% [27 hips]) and 110 patients (follow-up rate: $82 \%$ [118 hips]), in total 131 patients (followup rate: $82 \%$ [145 hips]), were available at a minimum of 15 years. Patients lost to followup in the pre-OA group were all female; four patients were lost at less than 5 years and one patient at less than 10 years after surgery. Patients lost to followup in the early-stage group included 22 females and two males. Ten patients were lost at less than 5 years, 12 patients at less than 10 years, and two patients at less than 15 years after surgery. The pre-OA group

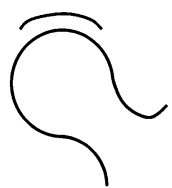

A

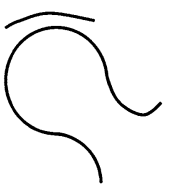

B

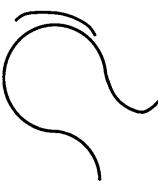

C

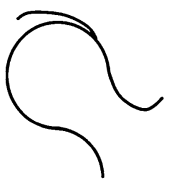

D
Fig. 1A-D Postoperative joint congruencies are divided into four grades: $\mathbf{A}=$ excellent, $\mathbf{B}=$ good, $\mathbf{C}=$ fair, $\mathbf{D}=$ poor. 
Table 1. Demographic and clinical characteristics of patients

\begin{tabular}{lll}
\hline Characteristic & Preosteoarthritis & Early stage \\
\hline Number of patients & $\begin{array}{c}21 \text { patients }(27 \\
\text { hips })\end{array}$ & $\begin{array}{c}110 \text { patients } \\
(118 \text { hips })\end{array}$ \\
Sex & 21 & 103 \\
Female & 0 & 7 \\
Male & 22.0 & 37.6 \\
Mean age at the time of & $(\mathrm{SD}, 6.5 ;$ range, & $(\mathrm{SD}, 9.4$; range, \\
$\quad$ surgery (years) & $15-51)$ & $13-58)$ \\
& 21.4 & 19.8 \\
Mean followup & $(\mathrm{SD}, 3.6 ;$ range, & $(\mathrm{SD}, 3.6$; range, \\
& $15-28)$ & $15-28)$ \\
Charnley category & & 22 \\
A & 2 & 88 \\
B & 19 & \\
\hline
\end{tabular}

consisted of 22 females with a mean age of 22 years (SD, 6.5). The early-stage group included 103 females and seven males with a mean age of 38 years (SD, 9.4) at the time of surgery. The mean followup periods were 21 years (SD, $3.6)$ in the pre-OA group and 20 years $(\mathrm{SD}, 3.6)$ in the early-stage group. According to Charnley's classification [2], there were two unilateral (Category A) and 19 bilateral cases (Category B) in the pre-OA group and 22 unilateral and 88 bilateral cases in the early-stage group (Table 1).

Previous surgery had been performed in 10 hips (7\%): open reduction for congenital dislocation in four hips, a varus proximal femoral osteotomy in four hips, and Chiari osteotomy [3] in two hips. Neurological disorders were present in three patients (three hips). Two patients had cerebral palsy and one had poliomyelitis.

\section{Surgical Technique}

Rotational acetabular osteotomies were performed according to the technique of Ninomiya and Tagawa [20]. The acetabulum is rotated in an anterolateral direction while maintaining contact between the osteotomy site in the pubis and ischium. This rotation provides a more horizontal weightbearing area with a target of a $0^{\circ}$ acetabular roof angle while returning the superiorly subluxated femoral head to a more normal position. One or two trapezoidal bone grafts are taken from the external wall of iliac wing and used to fill the anterior space between the ilium and the rotated acetabulum. Before 1996, we used two ceramic screws (Kyocera, Kyoto, Japan) to secure the osteotomy site. Thereafter, we used two poly-L-lactic acid screws (Gunze, Kyoto, Japan). Postoperative care included 6 days of bed rest followed by use of a wheelchair along with touch-down weightbearing, as tolerated, with the aid

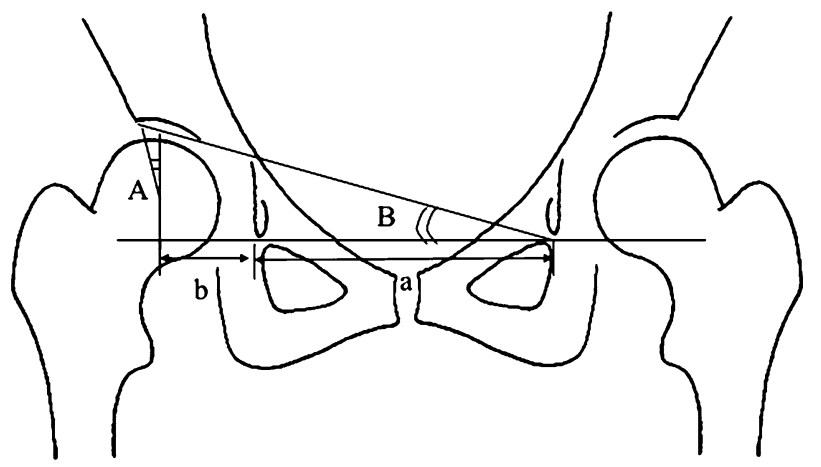

Fig. 2 Radiographic indices for evaluation of the hip are center-edge angle (A), acetabular roof angle (B), and head lateralization index, which is calculated with the distance between the teardrop and the center of rotation of the femoral head (b) divided by the half value of teardrop distance (a).

of crutches. Partial bearing of weight began 4 to 6 weeks after surgery, and full weightbearing started 5 to 6 months after surgery after resolution of the Trendelenburg sign.

\section{Clinical and Radiographic Evaluation}

Clinical followup was performed with the Merle d'Aubigne and Postel rating scale [16]. Pain, mobility, and walking ability were given scores ranging from 0 to 6 points. Higher scores reflected more normal performance. For patients whose hips were converted to THAs, we used the last score before the arthroplasty was performed.

Radiographic analyses included measurements of the center-edge angle [23], acetabular roof angle [15], and head lateralization index preoperatively and postoperatively (Fig. 2). Radiographic OA progression was defined as joint space narrowing less than $2 \mathrm{~mm}$. The radiographs were obtained in the supine position with a tube-to-film distance of $100 \mathrm{~cm}$ and tube orientation perpendicular to the table. The central beam was directed to the midpoint between the upper border of pubic symphysis and a horizontal line connecting both anterior iliac spines. To test the reproducibility of the radiographic measurements, three coauthors (TY, TS, SI) who were not involved in the surgical care of these patients measured the center-edge angle, acetabular roof angle, and head lateralization index in five randomly selected hips. Each observer measured each hip three times with an interval of 1 week between measurements, and the values were averaged. The data were analyzed for intraobserver and interobserver variances, and the coefficient of variation was calculated to be $<5 \%$. Therefore, the reproducibility of the measurements was considered reasonable.

Postoperative joint congruencies were divided into four grades [24]: excellent $=$ the curvature of the acetabulum and femoral head is almost identical and the joint space is 
adequately maintained; good $=$ curvature of the acetabulum and femoral head is not identical, but the joint space is adequate; fair $=$ partial narrowing of the joint space; and poor $=$ partial disappearance of the joint space (Fig. 1).

\section{Statistical Analysis}

The differences between two means were tested with use of the Wilcoxon rank test. With radiographic evidence of $\mathrm{OA}$ progression as the endpoint, nonparametric survivorship analyses with use of the log-rank test were performed to test seven variables: age, Charnley classification, the preoperative radiographic stage, the postoperative center-edge angle, the postoperative acetabular roof angle, the postoperative head lateralization index, and the postoperative joint congruency. The cumulative probabilities of radiographic signs of OA progression were estimated with use of the Kaplan-Meier product-limited method. The survivorship curves for various subgroups were compared with use of the log-rank test (StatView software; Abacus Concepts, Berkeley, CA, USA).

\section{Results}

\section{Clinical Results}

The mean clinical score improved very slightly, from 15 (SD, 0.8$)$ to 18 (SD, 1.1) points (95\% confidence interval [CI], -2.9 to $-2.0 ; \mathrm{p}<0.001)$ in the pre-OA group and from 15 (SD, 1.0) to 16 (SD, 2.1) (95\% CI, -2.0 to $-1.2 ; \mathrm{p}<$ 0.001 ) in the early-stage group at followup, mainly because of increased scores for pain. The clinical score of the pre-OA group was better than that of the early-stage group (95\% CI, $0.1-0.3 ; \mathrm{p}<0.001$; Table 2). A total of 14 patients (15 hips) whose radiographic stage was pre-OA in one patient (one hip) and early stage in 13 patients (14 hips), experienced a worsening of their Merle d'Aubigne and Postel score, from a mean of 15 (SD, 0.9) to 12 (SD, 1.6) (95\% CI, 1.8-3.3; p < $0.001)$. The clinical score at followup in the pre-OA group was $>15$ points in 27 hips and $>17$ points in 23 hips. In the early-stage group, it was $>15$ points in 103 hips and $>17$ points in 75 hips, but it was less than 15 points in 14 hips. In these 14 hips, eight patients (nine hips) underwent THA at a mean duration after rotational acetabular osteotomy of 20 $(\mathrm{SD}, 2.5)$ years. The mean age at the time of RAO was 46 $(\mathrm{SD}, 7.5)$ years.

\section{Radiographic Results}

Progression of OA occurred in two patients (two hips) in the pre-OA group and 23 patients ( 24 hips) in the early stage
Table 2. Clinical results

\begin{tabular}{|c|c|c|c|}
\hline Result & Pre-OA & Early stage & $\mathrm{p}$ value $(95 \% \mathrm{CI})$ \\
\hline \multicolumn{4}{|c|}{ Merle d'Aubigne and Postel score (mean \pm SD) } \\
\hline \multicolumn{4}{|c|}{ Before surgery } \\
\hline Pain & $3.6 \pm 0.8$ & $3.5 \pm 0.6$ & $0.52(0.4-1.7)$ \\
\hline ROM & $5.9 \pm 0.6$ & $5.9 \pm 0.3$ & $0.08(-0.3-0.02)$ \\
\hline Walk & $5.5 \pm 0.7$ & $5.3 \pm 0.7$ & $0.55(0.7-2.5)$ \\
\hline Total & $15 \pm 0.8$ & $15 \pm 1.0$ & $12(0.3-1.2)$ \\
\hline \multicolumn{4}{|c|}{ At followup } \\
\hline Pain & $5.9 \pm 0.4$ & $5.1 \pm 1.1$ & $<0.001(0.1-0.3)$ \\
\hline ROM & $6.0 \pm 0.2$ & $5.8 \pm 0.5$ & $<0.001(0.1-0.3)$ \\
\hline Walk & $5.9 \pm 0.4$ & $5.5 \pm 0.7$ & $<0.05(0.2-0.9)$ \\
\hline Total & $18 \pm 1.1$ & $16 \pm 2.1$ & $<0.001(0.1-0.3)$ \\
\hline
\end{tabular}

Total score: before surgery versus at followup; $p$ value $(95 \% \mathrm{CI}) ; \mathrm{p}<$ 0.001 ( -2.9 to -2.0$), \mathrm{p}<0.001$ ( -2.0 to -1.2$)$; OA = osteoarthritis; $\mathrm{CI}=$ confidence interval.

group. Of these, 17 patients (17 hips) progressed to an advanced stage and eight patients (nine hips) to end stage. Kaplan-Meier survivorship analysis, with radiographic signs of progression of $\mathrm{OA}$ as the endpoint, predicted a survival rate of $96 \%(95 \% \mathrm{CI}, 89 \%-100 \%)$ at 10 years and 20 years in the pre-OA group (Figs. 3A, 4A-D) and in the early-stage group, $89 \%(95 \% \mathrm{CI}, 83 \%-95 \%)$ at 10 years and $78 \%(95 \% \mathrm{CI}, 69 \%-87 \%)$ at 20 years (Figs. 3B, 5A-D). In all cases, the survival rate was $90 \%(95 \% \mathrm{CI}, 86-95)$ at 10 years and $82 \%$ (95\% CI, 75-90) at 20 years (Fig. 3C). With conversion to THA as the endpoint, the survival rate was $94 \%$ (95\% CI, 89-99) at 20 years.

In the pre-OA group, the mean center-edge angle improved from $1.6^{\circ}(\mathrm{SD}, 7.5)$ on preoperative radiographs to $32^{\circ}$ (SD, 7.3) on radiographs made 3 months postoperatively; the mean acetabular roof angle improved from $28^{\circ}$ (SD, 7.2) to $1.4^{\circ}$ (SD, 5.0), and the mean head lateralization index improved from $0.63(\mathrm{SD}, 0.07)$ to 0.58 (SD, 0.08). In the early-stage group, the mean center-edge angle improved from $0.4^{\circ}(\mathrm{SD}, 7.6)$ on preoperative radiographs to $31^{\circ}(\mathrm{SD}$, 7.0) on radiographs made 3 months postoperatively; the mean acetabular roof angle improved from $28^{\circ}(\mathrm{SD}, 7.8)$ to $3.0^{\circ}$ (SD, 7.0), and the mean head lateralization index improved from 0.65 (SD, 0.08) to 0.61 (SD, 0.10) (Table 3).

The postoperative joint congruency was excellent in 16 hips and good in 11 hips in the pre-OA group. In the earlystage group, congruency was excellent in eleven hips, good in 102 hips, and fair in five hips.

\section{Factors Associated With Osteoarthritis Progression}

Age at the time of surgery, postoperative center-edge angle, and postoperative joint congruency were found to 


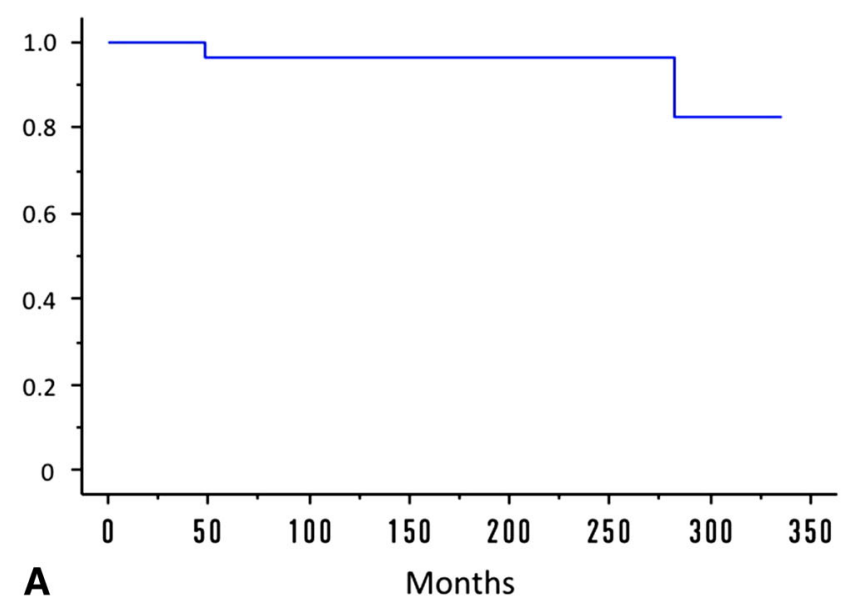

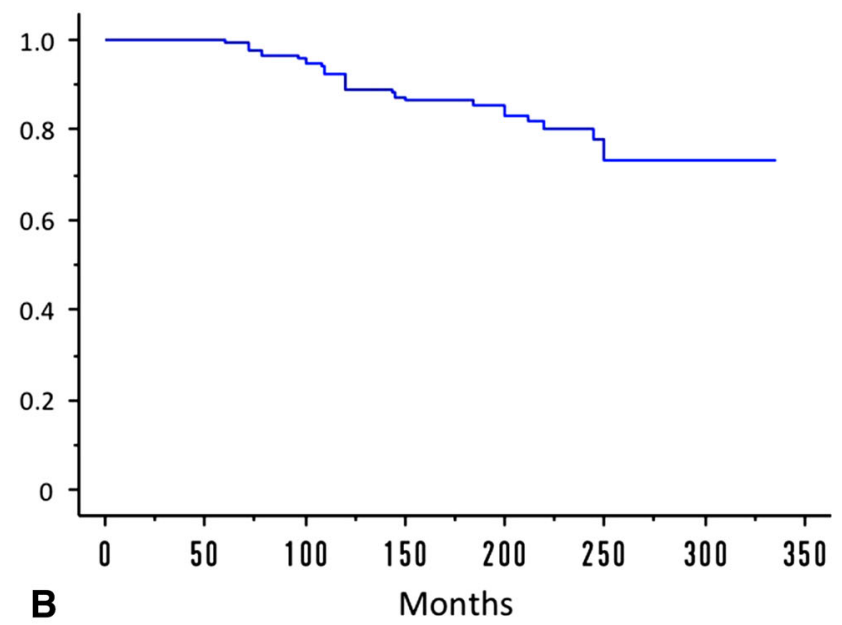

Fig. 3A-C Kaplan-Meier curve for the cumulative probability of OA progression. (A) The survival rate is $96 \%$ at 10 years and 20 years in the pre-OA group. (B) The survival rate is $89 \%$ at 10 years and $78 \%$

affect the radiographic OA progression in the early-stage group. In the pre-OA group, only the age at the time of surgery affected progression (Table 4). When these three factors were analyzed together in the early-stage group, postoperative joint congruency (hazard ratio, $12.1 ; 95 \% \mathrm{CI}$, $3.8-39 ; \mathrm{p}<0.001$ ) and age at surgery (hazard ratio, 4.6; $95 \%$ CI, $1.9-11 ; \mathrm{p}<0.01$ ) were found to be risk factors for radiographic OA progression, but postoperative centeredge angle (hazard ratio, 2.5; 95\% CI, 0.93-6.8; $\mathrm{p}=0.07$ ) was not. With the numbers available, there was no association of progression with Charnley classification, postoperative acetabular angle, or head lateralization index.

\section{Discussion}

Hip dysplasia is the most common cause of secondary OA $[1,8,10,18]$. To prevent the early onset of secondary OA, a number of surgical procedures have been proposed $[6,7$,

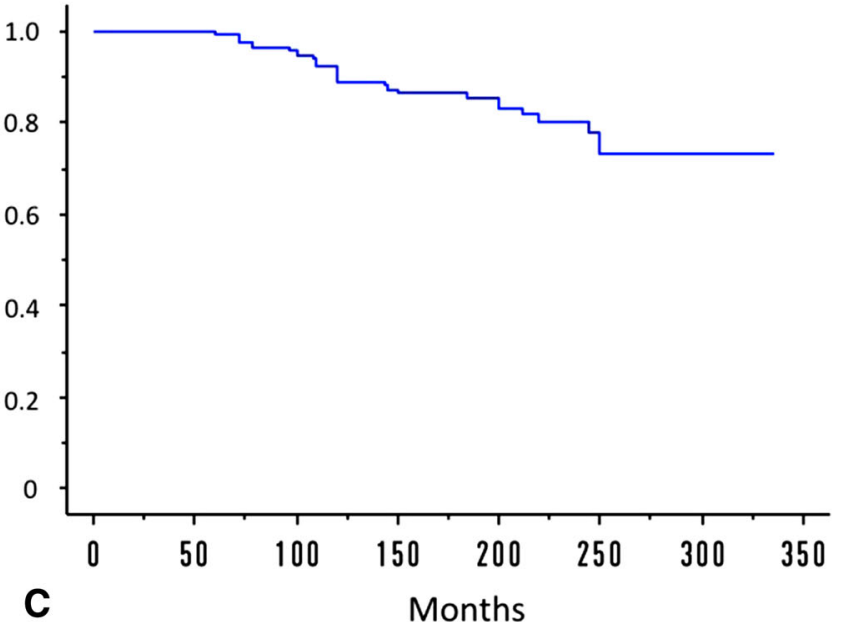

in the early-stage group. (C) The survival rate is $90 \%$ at 10 years and $82 \%$ at 20 years in all cases.

20, 21]. However, the optimal procedure for treating hip dysplasia in the patient with pre-OA or early OA has not been elucidated $[4,25]$. Here, we report on our experience with the rotational acetabular osteotomy initially described by Ninomiya and Tagawa [20]. We found that good clinical and radiographic outcomes were maintained even 20 years postsurgery. We also found that patient age and residual joint incongruency were risk factors for progression of OA.

This study had several limitations. First, loss to followup was approximately $18 \%$. In general, patients who are not accounted for are considered at greater risk for treatment failure; as such, the survivorship statistics provided here should be considered best-case estimates [5]. Another limitation was that radiographic evaluation was performed with only an AP radiograph and did not include a lateral radiograph such as a false profile view. We suspect that had those other images been available and evaluated for threedimensional femoral head coverage and joint congruency, 

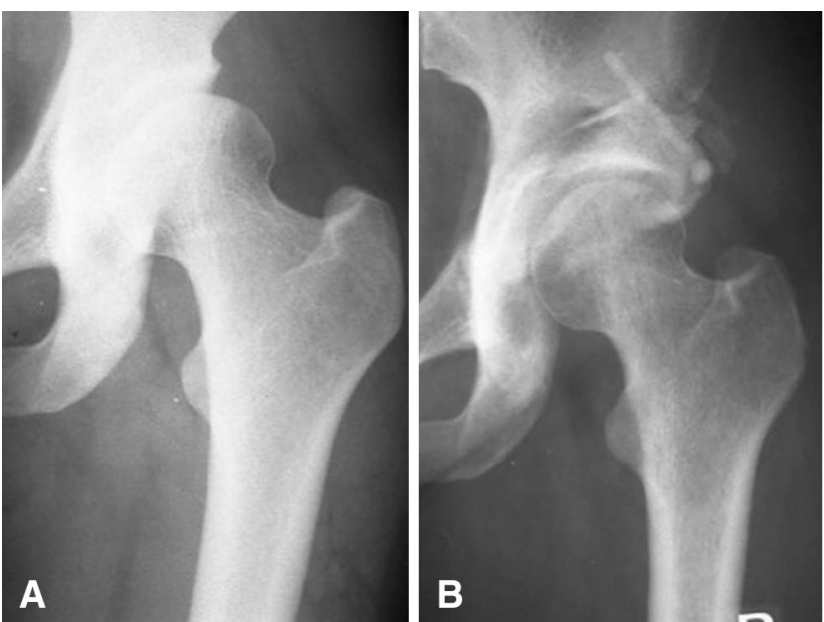

Fig. 4A-D Radiographs are shown of a 34-year-old woman with a dysplastic left hip with (A) a center-edge angle of $6^{\circ}$, acetabular roof angle of $30^{\circ}$, and head lateralization index of 0.60 without signs of OA (pre-OA stage). Charnley category was B. The Merle d'Aubigne
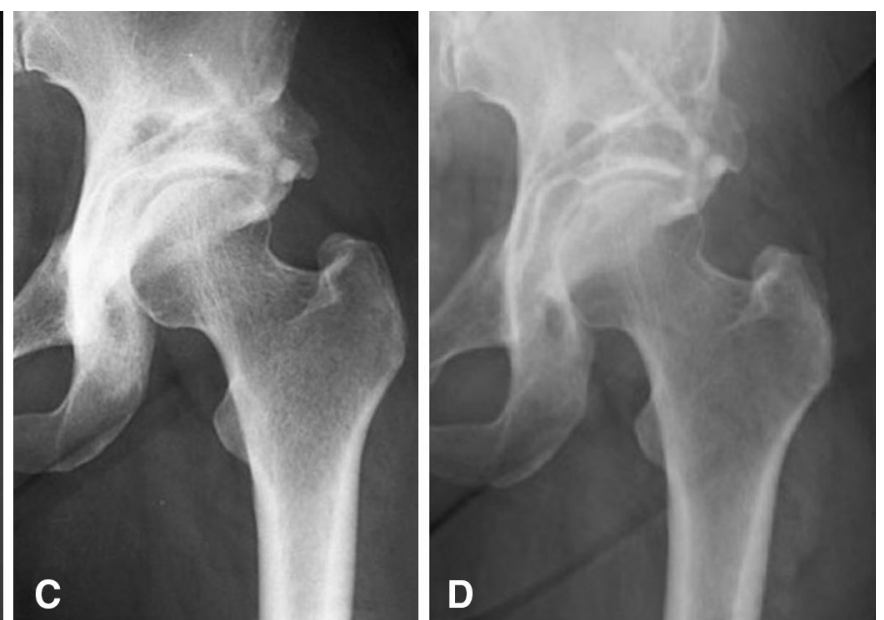

and Postel score was 15. (B) The postoperative center-edge angle was $33^{\circ}$, acetabular roof angle of $-3^{\circ}$, and head lateralization index of 0.60. (C) Ten-year and (D) 21-year followup; no OA changes were seen. At last followup, Merle d'Aubigne and Postel score was 18.
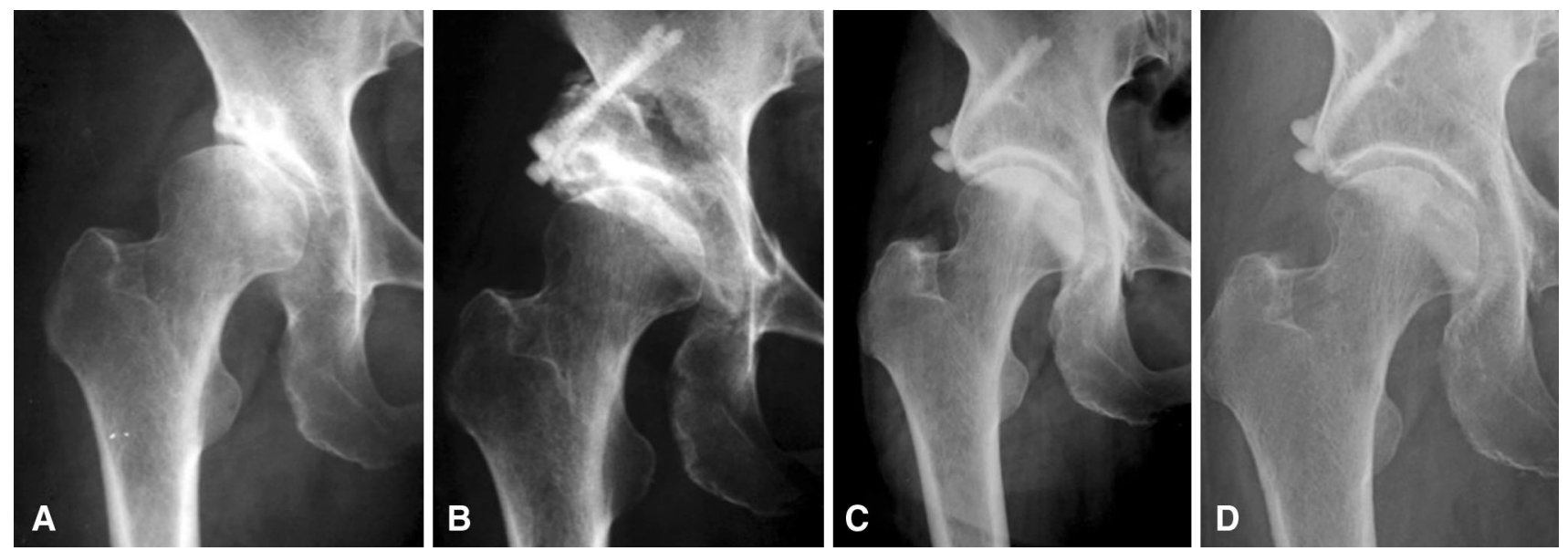

Fig. 5A-D Radiographs are shown of a 56-year-old woman with a dysplastic right hip with (A) a center-edge angle of $5^{\circ}$, acetabular roof angle of $32^{\circ}$, head lateralization index of 0.62 , and early-stage OA. Charnley category was B. The Merle d'Aubigne and Postel score was 14. (B) The postoperative center-edge angle was $32^{\circ}$, acetabular roof

we would have seen more evidence of residual incongruency. In addition, the average Japanese patient is smaller framed and substantially less likely to be overweight than a Western patient, and our favorable results might be the result of the light body weight of patients. Some of our nodifference findings on factors associated with OA progression such as Charnley category, preoperative radiographic stage, and indices of femoral coverage might indeed have been important but could not be identified statistically because of the insufficient sample size.

We found that clinical scores improved slightly after surgery and were maintained in a large majority of those angle of $0^{\circ}$, and head lateralization index of 0.58. (C) At 4-year followup, a remarkable joint modeling was observed. (D) At 23-year followup, no OA changes were seen. At last followup, Merle d'Aubigne and Postel score was 18.

patients who underwent rotational acetabular osteotomy. Kaneuji et al. [12] reported a long-term outcome of rotational acetabular osteotomy after a minimum of 20 years. In their report, the mean Harris hip score improved from preoperative points of 77 to final points of 90 in 23 hips with pre-OA and from 75 to 85 in 29 hips with early-stage OA. Hasegawa et al. [9] also reported a followup study of eccentric rotational acetabular osteotomy at a mean duration of 20 years. Although their report included 18 hips with pre-OA, 49 hips with early-stage OA, 40 hips with advanced-stage $\mathrm{OA}$, and 23 hips with simultaneous intertrochanteric valgus osteotomy, the mean preoperative 
Table 3. Radiographic results

\begin{tabular}{|c|c|c|c|}
\hline Results & Pre-OA & Early stage & $\mathrm{p}$ value $(95 \% \mathrm{CI})$ \\
\hline \multicolumn{4}{|l|}{ Before surgery } \\
\hline CE angle (mean, degrees, SD) & $1.6(7.5)$ & $0.4(7.6)$ & $0.60(0.48-1.7)$ \\
\hline Acetabular roof angle (mean, degrees, SD) & $28(7.2)$ & $28(7.8)$ & $0.53(0.47-1.6)$ \\
\hline Head lateralization index (mean, SD) & $0.63(0.07)$ & $0.65(0.08)$ & $0.43(0.45-1.5)$ \\
\hline \multicolumn{4}{|l|}{ After surgery } \\
\hline CE angle & $32(7.3)$ & $31(7.0)$ & $0.63(0.48-1.7)$ \\
\hline $\begin{array}{l}\mathrm{p} \text { value }(95 \% \mathrm{CI}) \text { in comparison between } \\
\text { before and after surgery }\end{array}$ & $0.001(-34$ to -27$)$ & $0.001(-32$ to -29$)$ & \\
\hline Acetabular roof & $1.4(5.0)$ & $3.0(7.0)$ & $0.38(-3.8$ to 1.4$)$ \\
\hline Angle & $0.001(24-30)$ & $0.001(24-27)$ & \\
\hline Head lateralization & $0.58(0.08)$ & $0.61(0.10)$ & $0.11(0.34-1.2)$ \\
\hline Index & $0.001(0.02-0.07)$ & $0.001(0.02-0.05)$ & \\
\hline
\end{tabular}

$\mathrm{OA}=$ osteoarthritis; $\mathrm{CI}=$ confidence interval; $\mathrm{CE}=$ center edge.

Table 4. Factors associated with OA progression with use of the log-rank test

\begin{tabular}{|c|c|c|c|c|}
\hline Variables & Pre-OA & & Early stage & \\
\hline \multicolumn{5}{|l|}{ Age at the time of surgery } \\
\hline Older 46 years & $1 \operatorname{hip}(1)$ & & 25 hips (10) & \\
\hline Younger than 46 years & 26 & (1) $\mathrm{p}<0.001$ & 93 & (14) $\mathrm{p}<0.05$ \\
\hline \multicolumn{5}{|l|}{ Charnley classification } \\
\hline A & 2 & $(0)$ & 22 & (5) \\
\hline B & 25 & (2) unable to assess & 96 & (19) $\mathrm{p}=0.65$ \\
\hline \multicolumn{5}{|c|}{ Postoperative center-edge angle } \\
\hline Over $31^{\circ}$ & 9 & (1) & 60 & (19) \\
\hline Less than $31^{\circ}$ & 18 & (1) $\mathrm{p}=0.544$ & 58 & (5) $\mathrm{p}=0.022$ \\
\hline \multicolumn{5}{|c|}{ Postoperative acetabular roof angle } \\
\hline Over $3^{\circ}$ & 10 & (1) & 49 & $(10)$ \\
\hline Less than $3^{\circ}$ & 17 & (1) $\mathrm{p}=0.921$ & 69 & (14) $\mathrm{p}=0.71$ \\
\hline \multicolumn{5}{|c|}{ Postoperative head lateralization index } \\
\hline Over 0.61 & 8 & $(0)$ & 73 & (14) \\
\hline Less than 0.61 & 19 & (2) unable to assess & 45 & (10) $\mathrm{p}=0.78$ \\
\hline \multicolumn{5}{|c|}{ Postoperative joint congruency } \\
\hline Excellent or good & 27 & (2) & 113 & (20) \\
\hline Fair & 0 & unable to assess & 5 & (4) $\mathrm{p}<0.001$ \\
\hline
\end{tabular}

Numbers in parentheses were progression of $\mathrm{OA} ; \mathrm{OA}=$ osteoarthritis.

Harris hip score of 70 points improved to a mean of 88 points. Thirty hips had a fair clinical outcome (Harris hip score $<80$ points). In both reports, patients with pre-OA showed better clinical sores than patients with early-stage or advanced-stage OA. In the present study, the mean Merle d'Aubigne and Postel score improved from 15 to 18 points in the pre-OA group and from 15 to 16 points in early-stage OA, mainly because of increased scores for pain. A total of 14 patients (15 hips) experienced a worsening of their score, from a mean of 14.5 to 12.0 . Of these patients, the preoperative radiographic stage was pre-OA in only one patient (one hip). In these patients, eight patients (nine hips) with early-stage OA had THAs. Our clinical findings thus corroborate those of previous reports.

Steppacher et al. [22] reported a mean 20-year followup study of periacetabular osteotomy, where $75 \%$ of Tönnis Grade 0 or 1 hips showed no radiographic signs of progression of OA. In their cases, a combined intertrochanteric valgus osteotomy was performed in $21 \%$ of patients, and a previous operative treatment had been performed in $31 \%$. 
A previous pelvic osteotomy such as a Chiari osteotomy would have distorted the hip morphology, and a periacetabular osteotomy would be technically difficult to perform. Kaneuji et al. [12] reported six hips (17\%) of 23 hips with pre-OA and 10 hips (34\%) of 29 hips with earlystage OA showed radiographic OA progression; and three hips in each group were converted to THA. Hasegawa et al. [9] reported six (33\%) of 18 hips with pre-OA and six (12\%) of 49 hips with early-stage OA showed radiographic OA progression, and a survival rate with conversion to THA as the endpoint was $97 \%$ at 20 years. In this study, two hips (7.4\%) of 27 hips with pre-OA and 24 hips (20\%) of 118 hips with early-stage OA showed OA progression. The survivorship analysis, with radiographic signs of progression of $\mathrm{OA}$ as the endpoint, predicted a survival rate of $82 \%$ at 20 years, with conversion to THA as the endpoint of $94 \%$ at 20 years in all cases. These results compare favorably with the results of Hasegawa et al. [9]. A small number of cases with previous surgeries (10 hips [7\%]) in this study compared with the number of cases $(31 \%)$ in the report of Steppacher et al. [22] might affect the outcome.

We found two factors associated with radiographic OA progression: age at the time of surgery (older than 46 years) and postoperative joint congruency (fair). Steppacher et al. [22] reported six factors predicting poor outcome: age at the time of surgery, preoperative Merle d'Aubigne and Postel score, preoperative anterior impingement sign, preoperative limp, preoperative radiographic OA grade, and postoperative exclusion index. Hasegawa et al. [9] described four factors leading to a poor outcome: a small $(<2$ $\mathrm{mm}$ ) preoperative minimum joint space, joint congruency, simultaneous intertrochanteric valgus osteotomy, and lateral subluxation of the femoral head postoperatively. Regarding joint congruency, several authors emphasized that postoperative good joint congruency is essential for a favorable outcome after periacetabular osteotomy and rotational acetabular osteotomy [11-13]. Patients with previous surgery or who need simultaneous femoral osteotomy are at risk of unfavorable postoperative joint congruency, and favorable long-term results cannot be expected. Murphy et al. [18] noted that no patient in whom the hip functioned well until the age of 65 years had had a center-edge angle of less than $16^{\circ}$, an acetabular index of depth to width of less than $38 \%$, an acetabular index of the weightbearing zone of more than $15^{\circ}$, uncovering of the femoral head of more than $31 \%$, or an acetabulum in which the most proximal point of the dome had been at the lateral edge (zero peak-to-edge distance). In our study, there were 24 patients ( 24 hips) whose age of older than 65 years at the final followup and radiographic OA progression was prevented in 14 patients $(58 \%)$. This result suggests that rotational acetabular osteotomy can change the natural history of the dysplastic hip.
In conclusion, rotational acetabular osteotomy is an effective surgical procedure for symptomatic dysplastic hips of pre- and early-stage OA with expected excellent or good postoperative joint congruency and additional longterm followup is needed to demonstrate an improvement over the natural history of hip dysplasia.

\section{References}

1. Aronson J. Osteoarthritis of the young adult hip: etiology and treatment. Instr Course Lect. 1986;35:119-128.

2. Charnley J. Numerical grading of clinical results. In: Charnley J, ed. Low Friction Arthroplasty of the Hip. Berlin, Germany: Springer; 1979:20-24.

3. Chiari K. Medial displacement osteotomy of the pelvis. Clin Orthop Relat Res. 1974;98:55-71.

4. Clohisy JC, Schutz AL, St John L, Schoenecker PL, Wright RW. Periacetabular osteotomy. A systematic literature review. Clin Orthop Relat Res. 2009;467:2041-2052.

5. Dettori JR. Loss to follow-up. Evid Based Spine Care J. 2011;2:7-10.

6. Eppright RH. Dial osteotomy of the acetabulum in the treatment of dysplasia of the hip. J Bone Joint Surg Am. 1975;57:1172.

7. Ganz R, Klaue K, Vinh TS, Mast JW. A new periacetabular osteotomy for the treatment of hip dysplasia. Clin Orthop Relat Res. 1988;232:26-36.

8. Harris WH. Etiology of osteoarthritis of the hip. Clin Orthop Relat Res. 1986;213:20-33.

9. Hasegawa Y, Iwase T, Kitamura S, Kawasaki M, Yamaguchi J. Eccentric rotational acetabular osteotomy for acetabular dysplasia and osteoarthritis. Follow-up at a mean duration of twenty years. J Bone Joint Surg Am. 2014;96:1975-1982.

10. Jingushi $S$, Ohfuji S, Sofue M, Hirota $Y$, Itoman M, Matsumoto T, Hamada Y, Shindo H, Takatori Y, Yamada H, Yasunaga Y, Ito H, Mori S, Owan I, Fujii G, Ohashi H, Iwamoto Y, Miyanishi K, Iga T, Takahira N, Sugimori T, Sugiyama H, Okano K, Karita T, Ando K, Hamaki T, Hirayama T, Iwata K, Nakasone S, Matsuura M, Mawatari T. Osteoarthritis hip joints in Japan: involvement of acetabular dysplasia. J Orthop Sci. 2011;16:156-164.

11. Kain MS, Novais EN, Vallim C, Millis MB, Kim YJ. Periacetabular osteotomy after failed hip arthroscopy for labral tears in patients with acetabular dysplasia. J Bone Joint Surg Am. 2011;93(Suppl 2):57-61.

12. Kaneuji A, Sugimori T, Ichiseki T, Fukui K, Takahashi E, Matsumoto T. Rotational acetabular osteotomy for osteoarthritis with acetabular dysplasia. J Bone Joint Surg Am. 2015;97:726-732.

13. Kim SD, Jessel R, Zurakowski D, Millis MB, Kim YJ. Anterior delayed gadolinium-enhanced MRI of cartilage values predict joint failure after periacetabular osteotomy. Clin Orthop Relat Res. 2012;470:3332-3341.

14. Leunig M, Siebenrock KA, Ganz R. Rationale of periacetabular osteotomy and background work. Instr Course Lect. 2001;50:229-238.

15. Massie WK, Howorth MB. Congenital dislocation of the hip. Part 1. Method of grading results. $J$ Bone Joint Surg Am. 1950;32:519-531.

16. Merle d'Aubigne R, Postel M. Functional results of hip arthroplasty with acrylic prosthesis. J Bone Joint Surg Am. 1954;36:451-475.

17. Millis MB, Murphy SB, Poss R. Osteotomies about the hip for the prevention and treatment of osteoarthrosis. Instr Course Lect. 1996;45:209-226. 
18. Murphy SB, Ganz R, Muller ME. The prognosis in untreated dysplasia of the hip. A study of radiographic factors that predict the outcome. J Bone Joint Surg Am. 1995;77:985-989.

19. Nakamura S, Ninomiya S, Takatori Y, Morimoto S, Umeyama T. Long-term outcome of rotational acetabular osteotomy: 145 hips followed for 10-23 years. Acta Orthop. 1998;69:259-265.

20. Ninomiya $S$, Tagawa $H$. Rotational acetabular osteotomy for the dysplastic hip. J Bone Joint Surg Am. 1984;66:430-436.

21. Steel HH. Triple osteotomy of the innominate bone. J Bone Joint Surg Am. 1973;55:343-350.

22. Steppacher SD, Tannast M, Ganz R, Siebenrock KA. Mean 20year followup of Bernerse periacetabular osteotomy. Clin Orthop Relat Res. 2008;466:1633-1644.
23. Wiberg G. Studies on dysplastic acetabula and congenital subluxation of the hip joint. With special reference to the complication of osteoarthritis. Acta Chir Scand Suppl. 1939;58:5-135.

24. Yasunaga Y, Kanazawa T, Ikuta Y, Takahashi K, Hisatome T. The state of the articular cartilage at the time of surgery as an indication rotational acetabular osteotomy. J Bone Joint Surg Br. 2001;83:1001-1004.

25. Yasunaga Y, Yamasaki T, Ochi M. Patient selection criteria for periacetabular osteotomy or rotational acetabular osteotomy. Clin Orthop Relat Res. 2012;470:3342-3354. 